\title{
Time Trend and prediction of Grade 2 Disability among new cases of leprosy
}

\section{in Nepal: A Statistical Modelling}

\author{
Sathian B1, Kumar A², Sreedharan J3, Banerjee $\mathbf{I}^{4}$, Roy B ${ }^{5}$, Rajesh E6
}

${ }^{1}$ Assistant Professor, Department of Community Medicine, Manipal College of Medical Sciences, Pokhara, Nepal.

${ }^{2}$ Assistant Professor, Department of Dermatology, Manipal College of Medical Sciences, Pokhara, Nepal.

${ }^{3}$ Assistant Director, Research Division, Gulf Medical University, Ajman UAE

${ }^{4}$ Assistant Professor, Department of Pharmacology, Manipal College of Medical Sciences, Pokhara, Nepal.

${ }^{5}$ Assistant Professor, Department of Physiology, Manipal College of Medical Sciences, Pokhara, Nepal.

${ }^{6}$ Assistant Professor, School of Behavioural Sciences, Mahatma Gandhi University, India.

\section{Chief Editor}

\section{Dr. R J Yadav}

Technical Editor

Dr. Nishida Chandrasekharan

Formatting Editor

Dr. Abhilash E S
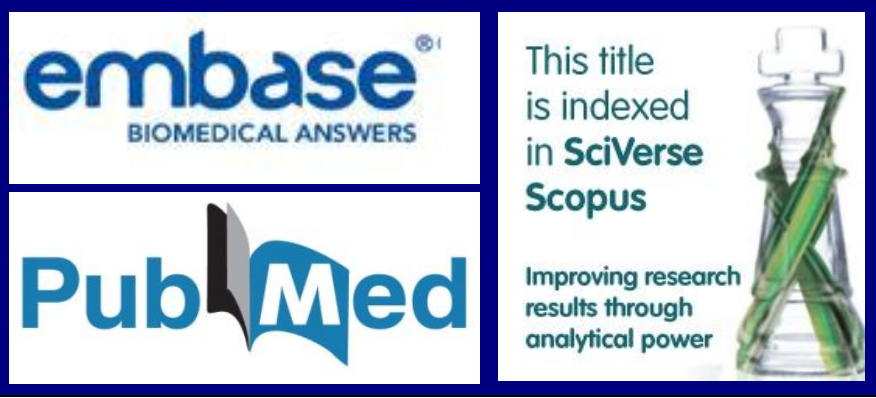

\section{Original Article}

\section{Corresponding Author}

Dr. Brijesh Sathian, PhD

Assistant Professor

Department of Community Medicine,

MCOMS, Pokhara, Nepal

E-mail: drsathian@gmail.com

\section{Abstract}

\section{Background}

It is estimated that globally there are around $\mathbf{2}$ million people with grade 2 disabilities attributed to leprosy. Objective of the study was to find out the time trends of Grade 2 Disability among the new cases of Leprosy in Nepal.

\section{Materials and Methods}

A retrospective study was carried out on the data collected from the Health ministry records of Nepal, between 2009 and 2013. The annual reported numbers of Grade 2 Disability among new cases of leprosy plotted in $y$-axis against the corresponding year in the x-axis. Curve fitting, also known as regression analysis, was used to find the "best fit" line or curve for a series of data points. Linear, Logarithmic, Inverse, Quadratic, and Cubic were chosen to fit to the obtained curve. Descriptive statistics and statistical modelling were used for the analysis and forecasting of data.

\section{Results}

Including the constant term from the equation, the inverse model was the best fit, for the forecasting of the Grade 2 Disability among new cases of leprosy in Nepal $\left[R^{2}=0.739\right.$, $\mathrm{p}=0.062]$. Using inverse model, it is estimated that 78 with $\mathrm{Cl}[0,170]$ of Grade 2 Disability among new cases of leprosy 
can be expected in Nepal by the year 2020 .

\section{Conclusion}

Our study proves Inverse model is the best fit for epidemiological modelling of Grade 2 Disability among the new cases of Leprosy in Nepal. Prevention of disabilities should begin with diagnosing leprosy.

Keywords: Grade 2 Disability, leprosy, statistical modelling, Nepal

\section{Background}

Leprosy is a chronic disease caused by Mycobacterium leprae. Official figures from 115 countries show that 232 857 new cases of leprosy reported in $2012^{1}$. Globally there are estimated 2 million Grade 2 Disability among the cases of Leprosy. The current strategy focuses on reducing the disease burden in terms of reducing the occurrence of new cases and occurrence of grade-2 impairments and disabilities along with the issues such as human rights, gender equality and initiatives to reduce stigma and discrimination faced by leprosy patients and their families ${ }^{1}$. Nepal is a leprosy eliminated country from early 2010. But the district level elimination of leprosy should be improved then only the constant trend of every year more than 3000 new reported leprosy cases will reduce. There were reported 3253 new cases and 2228 under treatment cases in 2013 with an estimated figure of 30,000 leprosy affected people who are in need of medical and social rehabilitation. Leprosy control division of Nepal has been implementing various programmes related to improving the knowledge regarding leprosy, capacity building, active case detection and management. But the importance is given to complete treatment and prevent Grade 2 Disability through early case detection. Case based surveillance both in high and low endemic districts required for attaining these goals ${ }^{2}$.

Chen XS et al. used exponential model to predict the elimination of leprosy in leprosy endemic areas of China. ${ }^{[3]}$ Sathian B et al. had done several successful attempts to forecast communicable and non-communicable diseases in Nepal $^{4-9}$. Objective of the study was to find out the time trends of Grade 2 Disability among the new cases of Leprosy in Nepal.

\section{Material and Methods}

\section{Study setting}

A retrospective study was carried out on the Grade 2 Disability among new cases of leprosy data collected from the Health ministry records of Nepal, between 2009 and 2013.

\section{Grading}

Disability is a broad term covering any impairment, activity limitation or participation restriction offering a person. Grading 0 means no visible disability found. Grading 1 means that loss of sensation has been noted in the palm of the hands or sole of the feet. Grading 2 means that visible damage or deformities is noted in eyes or hands or feet.

\section{Study methodology}

The annual reported numbers of Grade 2 Disability among new cases of leprosy plotted in $y$-axis against the corresponding year in the $\mathrm{x}$-axis. Curve fitting, also known as regression analysis, was used to find the "best fit" line or curve for a series of data points. Linear, Logarithmic, Inverse, Quadratic, and Cubic were chosen to fit to the obtained curve.

\section{Curve Fitting Method}

The Curve Estimation procedure produces curve estimation regression statistics and related plots for 10 different curve estimation regression models. A separate model is produced for each dependent variable. You can also find out predicted values, residuals, and prediction intervals as new variables.

For each model, we can find out the regression coefficients, multiple $R, R^{2}$, adjusted $R^{2}$, standard error of the estimate, analysis-of-variance table, predicted values, residuals, and prediction intervals. Models: linear, logarithmic, inverse, quadratic, cubic, power, compound, S-curve, logistic, growth, and exponential.

\section{Linear Model}

Model whose equation is

$Y=b_{0}+\left(b_{1} \times t\right)$

\section{Logarithmic Model}

Model whose equation is

$Y=b_{0}+\left[b_{1} \times \ln (t)\right]$

\section{Inverse Model}

Model whose equation is

$Y=b_{0}+\left[\frac{b_{1}}{t}\right]$

\section{Quadratic Model}

Model whose equation is

$$
Y=b_{0}+\left(b_{1} \times t\right)+\left(b_{2} \times t^{2}\right)
$$

The quadratic model can be used to model a series that "takes off" or a series that dampens.

\section{Cubic Model}

Model that is defined by the equation

$$
Y=b_{0}+\left(b_{1} \times t\right)+\left(b_{2} \times t^{2}\right)+\left(b_{3} \times t^{3}\right)
$$

\section{Compound Model}

Model whose equation is

$$
Y=b_{0} \times b_{1}^{t}
$$




\section{Power Model}

Model whose equation is

$$
Y=b_{0} \times\left(t^{b_{1}}\right)
$$

or

$\ln (Y)=\ln \left(b_{0}\right)+\left(b_{1} \times \ln (t)\right)$

\section{S-curve Model}

Model whose equation is

$$
Y=\exp \left(b_{0}+\frac{b_{1}}{t}\right)
$$

\section{Growth Model}

Model whose equation is

$$
Y=\exp \left(b_{0}+b_{1} t\right)
$$

\section{Exponential Model}

Model whose equation is

$$
Y=b_{0} e^{b_{1} t}
$$

F-test was used for selecting the best fitting curve for the testing of hypothesis. P-value was taken as significant when $<0.10$ (two-tailed). $R^{2}$ value $>0.70$ was taken as significantly better for prediction ${ }^{10}$.

The decision regarding the selection of a suitable prediction approach is governed by the relative performance of the models for monitoring and prediction. It should also adequately interpret the phenomenon under study. Inverse model selected here could closely fit curves for estimated and reported Grade 2 Disability among new cases of leprosy [Figure 1]. While building model, the extremities (maximums and minimums) play a great role. If the points are scattered more, the curve tries to adjust with maximum number of observed points. The inverse model represented by the equation

$Y=b_{0}+\left[\frac{b_{1}}{X}\right]$

where $b_{0}$ is the constant term and $b_{1}$ are coefficient terms ${ }^{11,12}$. Where $Y$ is the number of number of Grade 2 Disability among new cases of leprosy annually and $X$ is the corresponding year; 1=2009, 2=2010, 3=2011, 4=2012 and so on.

\section{Statistical Analysis and Data Analysis:}

The data was analysed using Excel 2003, R 2.8.0, Statistical Package for the Social Sciences (SPSS) for Windows Version 16.0 (SPSS Inc; Chicago, IL, USA) and EPI Info 3.5.1 windows version. A $p$-value of $<0.10$ (two-tailed) was used to establish statistical significance.

\section{Result}

The data was modelled using the curve fitting method. [Tables 1 and Figure 1] depicts the model summary and the parameter estimates including the constant term for different models. Including the constant term in the equation, the inverse model was the best fit, for the forecasting of Grade 2 Disability among new cases of leprosy $\left[R^{2}=0.739, p=0.062\right]$. The inverse model equation below contain $\mathrm{X}$ and $\mathrm{Y}$, which are the corresponding year and frequency of Grade 2 Disability among new cases of leprosy respectively. $b_{0}$ and $b_{1}$ calculated from the observed data.

Table 1: Model summary and parameter estimates including the constant term for different models for the reported number of Grade 2 Disability among new cases of leprosy in Nepal

\begin{tabular}{|c|c|c|}
\hline \multirow{2}{*}{ Equation } & \multicolumn{2}{|c|}{ Model Summary } \\
\cline { 2 - 3 } & R Square & p-value \\
\hline Linear & 0.402 & 0.250 \\
\hline Logarithmic & 0.577 & 0.136 \\
\hline Inverse & 0.739 & 0.062 \\
\hline Quadratic & 0.642 & 0.358 \\
\hline Cubic & 0.949 & 0.284 \\
\hline Compound & 0.349 & 0.294 \\
\hline S & 0.662 & 0.094 \\
\hline Growth & 0.349 & 0.294 \\
\hline
\end{tabular}

The equation for the inverse model for the reported number of Grade 2 Disability among new cases of leprosy in Nepal is

$Y=68.735+\left[\frac{105.689}{X}\right]$

(Where $Y$ is the number of number of reported Grade 2 Disability among new cases of leprosy in Nepal annually and $X$ is the corresponding year; $1=2009,2=2010,3=2011$, 4=2012 and so on) 
Figure 1: Fitted curves for Grade 2 Disability among new cases of leprosy

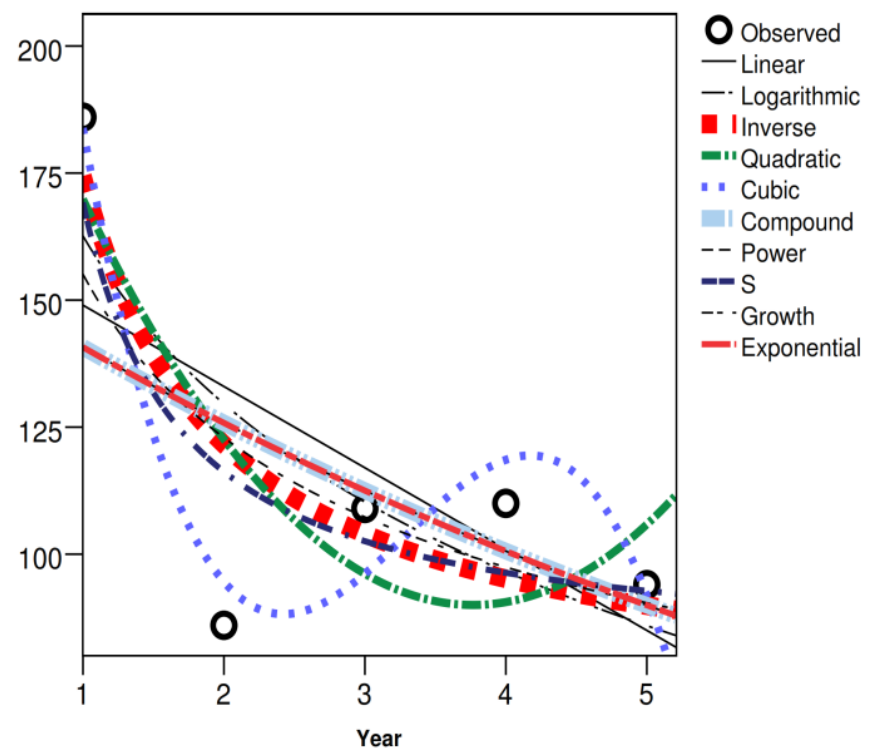

Table 2: Reported and estimated number of Grade 2 Disability among new cases of leprosy.

\begin{tabular}{|c|c|c|c|c|}
\hline Year & $\begin{array}{c}\text { Observed } \\
\text { cases }\end{array}$ & $\begin{array}{c}\text { Estimated } \\
\text { Cases }\end{array}$ & $\begin{array}{c}\text { Lower } \\
\text { limit }\end{array}$ & $\begin{array}{l}\text { Upper } \\
\text { Limit }\end{array}$ \\
\hline 2009 & 186 & 174 & 71 & 278 \\
\hline 2010 & 86 & 122 & 39 & 204 \\
\hline 2011 & 109 & 104 & 21 & 187 \\
\hline 2012 & 110 & 95 & 10 & 181 \\
\hline 2013 & 94 & 90 & 3 & 177 \\
\hline 2014 & & 86 & 0 & 175 \\
\hline 2015 & & 84 & 0 & 174 \\
\hline 2016 & & 82 & 0 & 173 \\
\hline 2017 & & 80 & 0 & 172 \\
\hline 2018 & & 79 & 0 & 171 \\
\hline 2019 & & 78 & 0 & 171 \\
\hline 2020 & & 78 & 0 & 170 \\
\hline
\end{tabular}

Using the equation, reported numbers of Grade 2 Disability among new cases of leprosy in Nepal were estimated [Table 2].
Discussion:

\section{Statistical Modelling}

A plot is a graphical representation of the collected data (independent and dependent variables) involved in a study. The relationship between these variables is then assessed by connecting the 'points' with a line. Though very true, this association cannot be relied upon to predict the future trend of this data. Now a 'model', which 'fits best' to the observed data has to be worked out. This is then 'fitted' and used to replace the existing set of data points as the appropriate model'. After 'modelling' the observed data, this model can be used to predict future trend of the dependent variable for a given change in the other. The foregoing statement covertly mentions several requirements which often ensure confident achievement in any subsequent extrapolation from the model. The model selected must be the most appropriate for the collected data. A usable and understandable curve-fitting method is to be available from which the model facts those are reflective of future behaviour can be obtained ${ }^{13,14}$.

\section{Model Building}

Using the curve fitting method, we estimated the number and trend of reported Grade 2 Disability among new cases of leprosy at Nepal from the year 2009 to 2020. Inverse model provided closely fitted curves for estimated and reported Grade 2 Disability among new cases of leprosy (Figure 1). Our study is contradictory to the other studies done in communicable and non communicable diseases by Sathian B et al. which showed cubic and quadratic models are the best fitted models ${ }^{4-12}$.

While building model, the extremities (maximums and minimums) play a great role $e^{4-6}$. If the points are scattered more, the curve tries to adjust with maximum number of observed points. Therefore, it might give over- and underestimation inevitably, but that is not the case in all the situations. A sudden annual decrease and increase in the trend is possible, as the curve cannot exactly connect these data points because of its shape. For adjusting the over-and under-estimation, the model gave wide confidence intervals in case of some years (Table 2$)^{4-7}$. In our study, the future annual reported Grade 2 Disability among new cases of leprosy (Table 2) shows a decreasing trend.

\section{Leprosy and grade $\mathbf{2}$ disability management}

Leprosy is a leading cause of permanent disability among communicable diseases. An estimated three million people live with disability due to leprosy and it is expected that up to one million people will continue to suffer from disability in the next decades ${ }^{15,16}$. The International Classification of Functioning, Disability and Health (ICF) definition goes beyond the concept of considering disability in medical terms only, and recognizes the social context of disability and it lead to a negative image towards leprosy. Leprosy patients with grade 2 disability fear about stigmatization and discrimination, and experience serious psychosocial and economic problems ${ }^{17-19}$.

Mycobacterium leprae residues can remain for many years after MDT that can lead to development of disability due to 
nerve injury in these patients. So, the primary health care (PHC) medical officers should be trained to identify possible development of lepra reaction and disabilities, so that they can refer such cases to the hospitals which have advanced facilities. There is an urgent need of rehabilitation for the patients who have already developed disabilities which are irreversible which emphasise on legal, social, religious, medical and occupational aspects.

\section{Limitation of the study}

Inverse model is the best fit for epidemiological modelling of Grade 2 Disability among the new cases of Leprosy in Nepal but the number of cases is very less so we had to set the cut off point for the $p$ value as 0.1 instead of 0.05 . Scientific literatures show a $p$ value up to 0.2 is acceptable to fix for cut off points in testing of hypothesis.

\section{Conclusion}

Our study proves inverse model is the best fit for epidemiological modelling of Grade 2 Disability among the new cases of Leprosy in Nepal. Prevention of disabilities should begin with early diagnosis and treatment. Nepal need a community level approach towards leprosy patients which will reduce and possibly eliminate leprosy, grade 2 disability and stigma.

\section{What's known?}

1. Annual reported Grade 2 Disability among new cases of leprosy from 2009 to 2013

2. Trend of annual reported Grade 2 Disability among new cases of leprosy up to 2013

\section{What's new?}

1. Annual reported Grade 2 Disability among new cases of leprosy from 2014 to 2020

2. Trend of annual reported Grade 2 Disability among new cases of leprosy up to 2020

\section{Key Messages}

Curve fitting method is a powerful tool to forecast epidemiological data. Inverse model is the best fit for epidemiological modelling of Grade 2 Disability among the new cases of Leprosy in Nepal. The future annual reported Grade 2 Disability among new cases of leprosy shows a decreasing trend in Nepal.

\section{Future scope of the study}

There is an urgent need of qualitative research in this area which can also amend a counseling programme with the help of Psychiatrists to reduce the problems of leprosy patients with grade 2 disability viz. stigmatization, discrimination, and serious psychosocial and economic problems.

\section{Author's Contribution}

BS designed the study, collected the data and drafted manuscript. JS helped in designing the study and revision of the manuscript. AK critically revised the manuscript. IB and BR assisted in manuscript write up. JS and RE helped in data analysis and interpretation. All the authors approved the final document.

\section{Acknowledgements}

We thank Dr S.B. Dixit, Professor \& Head, Department of Community Medicine, Manipal College of Medical Sciences (MCOMS), Nepal for all guidance, proposition and cooperation in writing this paper. We are grateful for the support given by Dr. B.M. Nagpal, Dean and CEO, MCOMS, Nepal. We are also thankful to Dr. Shishir Gokhale, Director of Basic Sciences and Head of the Department of Microbiology for giving us constant support.

\section{Conflict of interest}

None

\section{References}

1. WHO | Leprosy [Internet]. WHO. [online] 2014 [cited 2014 May 15]. Available from: http://www.who.int/mediacentre/factsheets/fs101/en/

2. Leprosy Control Division [Internet]. Nepal: Leprosy Control Division. [online] 2014 [cited 2014 February 15]. Available from: http://lcd.gov.np/

3. Chen XS, Li WZ, Jiang C, Ye GY. Prediction of elimination of leprosy in leprosy endemic areas of China. Indian J Lepr 1999;7:189-201.

4. Sathian B, Fazil A, Sreedharan J, Pant S, Kakria A, Sharan $K$, et al. Statistical modelling and forecasting of cervix cancer cases in radiation oncology treatment: a hospital based study from Western Nepal. Asian Pac J Cancer Prev 2013;14:2097-100.

http://dx.doi.org/10.7314/APJCP.2013.14.3.2097 PMid:23679325

5. Sathian B, Sreedharan J, Sharan K, et al. Statistical modelling technique in forecasting of palliative oncotherapy load in hospitals. Nepal J Epidemiol 2010; 1: 38-43.

http://dx.doi.org/10.3126/nje.v1i1.4111

6. Sathian B, Bhatt CR, Jayadevan S, Ninan J, Baboo NS, Sandeep G. Prediction of cancer cases for a hospital in Nepal: a statistical modelling. Asian Pac J Cancer Prev 2010; 11: 441-5.

PMid:20843131

7. Sathian B, Sreedharan J, Sharan K, Baboo NS, Ninan J, Joy $T$, et al. Forecasting breast cancer cases requiring radiotherapy at a teaching hospital in Nepal. J Clin Diagn Res 2010; 4: 2378-83.

8. Sathian B. Statistical modelling of HIV/AIDS in Nepal: a necessary enquiry. Nepal J Epidemiol 2011; 1: 74-6. http://dx.doi.org/10.3126/nje.v1i3.5568

9. Sathian B, Sreedharan J, Mittal A, Baboo NS, Chandrasekharan N, Devkota $S$, et al. Statistical modelling and forecasting of reported HIV cases in Nepal. Nepal J Epidemiol 2011; 1: 107-11. 
http://dx.doi.org/10.3126/nje.v1i3.5570

10. Sathian B, Sreedharan J, Devkota S. Material \& methods. In: irusu, editor. Statistical Modelling of Reported HIV Cases in Nepal, 1st ed. Germany: LAP LAMBERT Academic Publishing; 2013. p. 4-32.

11. Sathian B, Sreedharan J, Sharan K. Material \& methods. In: irusu, editor. Breast Cancer Cases forecasting for Radiotherapy in Western Nepal, 1st ed. Germany: LAP LAMBERT Academic Publishing; 2013. p. 4-12.

12. Sathian B, Sreedharan J. Statistical Methods for Modeling HIV/AIDS in India. WebmedCentral Biostatistics 2012;3:WMC003336.

13. Ihaka R, Gentleman R. R: A language for data analysis and graphics. J Comput Graph Stat 1996;5:299-314. http://dx.doi.org/10.2307/1390807

http://dx.doi.org/10.1080/10618600.1996.10474713

14. Murrell P, Ihaka R. An approach to providing mathematical annotation in plots. J Comput Graph Stat 2000;9:582-99.

http://dx.doi.org/10.2307/1390947

http://dx.doi.org/10.1080/10618600.2000.10474900

15. Britton WJ, Lockwood DN. Leprosy. Lancet 2004;363:1209-19.

http://dx.doi.org/10.1016/S0140-6736(04)15952-7

16. Meima A, van Veen NH, Richardus JH. Future prevalence of WHO grade 2 impairment in relation to incidence trends in leprosy: an exploration. Trop Med Int Health 2008;13:241-46.

http://dx.doi.org/10.1111/j.1365-3156.2007.01996.x

PMid:18304271

17. Rafferty J. Curing the stigma of leprosy. Lepr Rev 2005;76:119-26.

PMid:16038245

18. Cross $\mathrm{H}$, Choudhary R. STEP: An intervention to address the issue of stigma related to leprosy in Southern Nepal. Lepr Rev 2005;76:316-24. PMid:16411511

19. Scott J. The psychosocial needs of leprosy patients. Lepr Rev 2000;71:486-491.

PMid:11201903

Article Information

\section{Article history}

\begin{tabular}{|l|l|}
\hline Received & $2^{\text {nd }}$ May 2014 \\
\hline Received in revised form & $15^{\text {th }}$ June 2014 \\
\hline Accepted & $26^{\text {th }}$ June 2014 \\
\hline
\end{tabular}

